Original article

\title{
Testing a diabetes keotacidosis simulation in critical care nursing: A randomized control trial
}

\author{
Melba Sheila D'Souza (RN, CMSN(C), PhD, MPhilN, MScN, BScN) ${ }^{\mathrm{a}, * *}$, \\ Leodoro Jabien Labrague (RN, PhD, MAN, BSN) ${ }^{\mathrm{b}}$, Subrahmanya Nairy Karkada (PhD, MSc, BSc) ${ }^{\mathrm{c}}$, \\ Kader Parahoo (RN, PhD) ${ }^{\mathrm{d}}$, Ramesh Venkatesaperumal $(\mathrm{RN}, \mathrm{MScN}, \mathrm{BScN})^{\mathrm{e}}$

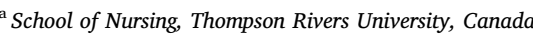 \\ ${ }^{\mathrm{b}}$ College of Nursing, Sultan Qaboos University, Sultanate of Oman, Oman \\ ${ }^{\mathrm{c}}$ Integrated Planning and Effectiveness, Thompson Rivers University, Canada \\ ${ }^{\mathrm{d}}$ Nursing and Health Research, Director, Institute of Nursing and Health Research, Faculty of Life and Health Science, University of Ulster, Cromore Road, Coleraine, BT52 \\ $1 S A, U K$ \\ ${ }^{\mathrm{e}}$ York University, Toronto, Canada
}

\section{A R T I C L E I N F O}

\section{Keywords:}

High-fidelity simulation

Diabetes ketoacidosis

Satisfaction

Self-confidence

Critical thinking

Nursing

\begin{abstract}
A B S T R A C T
Background: Integrating high fidelity simulation while teaching diabetes ketoacidosis would ensure a controlled therapeutic milieu for nursing students to practice.

Purpose: To evaluate the effectiveness of simulation teaching intervention for diabetes ketoacidosis in critical care nursing for undergraduate students' in a public university.

Methods: A simple, two-arm (parallel) randomized controlled trial was conducted in a national public university. A total of 164 nursing students were recruited and randomly assigned to two groups. The simulation group $(\mathrm{N}=82)$ participated in the diabetes ketoacidosis high-fidelity simulation teaching intervention compared to the control group $(\mathrm{N}=82)$ who were exposed to patient assignments on a clinical day on an acute medical unit. The primary outcomes were assessed using the Student Satisfaction and Self Confidence in Learning, Simulation Design Scale, Educational Practice Questionnaire, Critical Thinking Skills Tool and California Critical Thinking Skill Test from 2015 to 2016.

Results: The students in the randomized control trial have had significantly higher scores on Student Satisfaction, and Self Confidence in Learning, Simulation Design, Educational Practice, Critical thinking skills and Critical Thinking Skill post-test mean scores. Younger age groups who had higher satisfaction had better selfconfidence and a positive perception of the simulation design and education practice, which reflected better learning outcomes in the simulation group compared to the control group.

Conclusions: This study supports the use of high-fidelity simulation scenarios as a teaching-learning strategy that is useful for students to assess, plan, intervene and evaluate in emergencies like diabetes ketoacidosis.
\end{abstract}

\section{Introduction}

Registered nurses are expected to use evidence-informed knowledge and its application to evidence-informed practice to provide safe and quality patient care using capabilities and skills. When students practice in high-risk settings such as a critical care unit, they often assume the role of an observer rather than that of an active learner with implications on patient safety and its effect on professional liability. Through mimicking actual clinical simulations, students can be exposed to highrisk patient care situations and recognizing critical problems. ${ }^{1} \mathrm{~A}$ wide variety of simulated patient care experiences can be provided for developing critical thinking for students in critical care nursing. Highfidelity simulation helps to improve the knowledge of African-American nursing students exposed to simulation pedagogy. ${ }^{2}$ With an increasing demand for the growing number of student nurses and nursing programs compared to the static clinical placements, there is an acute shortage of acquiring acute and critical care settings for student practice in the Sultanate of Oman.

Simulation can help novice students to learn critical care nursing skills, develop core competencies and master the standards of

\footnotetext{
* Corresponding author.

E-mail addresses: mdsouza@tru.ca (M.S. D'Souza), leodoroj@squ.edu.om (L.J. Labrague), ksnairy@gmail.com (S.N. Karkada), ak.parahoo@ulster.ac.uk (K. Parahoo), vramesh@my.yorku.ca (R. Venkatesaperumal).
} 
professional practice. Simulation may help to integrate active learning ${ }^{3}$ as a useful educational strategy, ${ }^{4}$ which allows students to learn about communication skills. ${ }^{5}$ This simulated learning helps instill safe practice in undergraduate nursing students for the transferability of skills into safe, competent nursing care. However, there have been no studies to evaluate the effectiveness of diabetes ketoacidosis simulation using high-fidelity simulation in nursing students. The study aimed to evaluate the effectiveness of simulation teaching intervention for diabetes ketoacidosis among undergraduate student nurses' in a critical care nursing setting in a public hospital university.

\section{Methods}

\subsection{Study design}

A simple, two-arm (parallel) randomized controlled trial (RCT) design was used to test the efficacy of simulation teaching intervention in critical care nursing for students at a public university.

\subsection{Setting}

The target population consisted of students enrolled in the critical care nursing theory and clinical course from September 2015 to April 2016 in the public university situated in the Sultanate of Oman. The clinical simulation laboratory (CSL) comprised a well-controlled simulation room with an audio-visual recorder, an operational office with a microphone, and an observation/debriefing room operated by qualified nursing simulation technicians. In the comparison group, students were exposed to an acute medical unit. The inclusion criteria were students who had registered in the critical care nursing theory and clinical course from 2015 to 2016, had no prior high-fidelity simulation, had no experience with diabetes ketoacidosis, and who were willing to participate in the study. The students were well-informed about voluntary participation and had the freedom to withdraw at any time during the study.

\subsection{Sample size}

With a confidence level of $95 \%$, a confidence interval or margin of error of $7 \%$, an effect size of 0.80 and a level of significance (alpha) level of 0.05 , the calculated sample size was 142 participants from a total population of 580 students. A total of 164 participants were estimated to improve retention and reduce attrition (Fig. 1).

\subsection{Randomization}

A computer-based random sequence generation algorithm in SAS programming was presented by an external researcher to generate the random sequence of participant allocation (e.g. A, B, B, A, A, B, B, B ...). The external researcher prepared sequentially numbered opaque envelopes, each of which contained a card that was marked with the group assignment (coded as A or B) according to the randomly generated sequence. The computer algorithm performed block randomization with a randomly assigned block size of 5 to the simulation group (A group) or the control (B group) group using the randomization in a permuted block for a block size of 4 using equal numbers to each treatment. The macro generated 16 randomized block allocations each for the CCN course, and a uniform distribution was planned in this open trial using a randomization scheme of permuted blocks (Fig. 1).

When the recruitment process started, and a consenting student was considered eligible to participate in the RCT, the next sealed envelope in the sequence was opened, and the participant was assigned to the study group indicated on the card. The details of the sequentially numbered blocks were contained in a set of opaque, sealed envelopes each bearing on the outside the assigned number to prevent confounding bias. The sealed envelopes had the computer-generated numbers in advance and were opened sequentially, only after the student's number is written on the appropriate envelope. A single-blind and concealment of allocation consisted of Block 1 randomized ten students, with the first five assigned to the simulation group and the last five appointed to control group. For each week, ten students were randomly assigned to the simulation group, and ten students were randomly allotted to the control group on a randomly assigned block specified for over 8 weeks from September 2015 to April 2016 until the sample size $(\mathrm{N}=164)$ was met.

The confounding variable was a past clinical experience which was controlled for in the design and analysis. Randomization was used to control the prior clinical experience using a well-designed RCT and blocked randomization to study the effect of simulation teaching approach on improving primary outcomes like satisfaction and self-confidence in learning, critical thinking disposition and critical thinking skills. The RCT provided an equal number of students between the simulation and control groups to show that any differences between the two groups were due to chance rather than the clinical experience.

\subsection{Outcome measures, validity and reliability}

The National League of Nursing (NLN) Laerdal Group ${ }^{6}$ standardized survey questionnaires like the Student Satisfaction and Self Confidence in Learning, Simulation Design Scale, Educational Practice Questionnaire, Critical Thinking Skills Tool and California Critical Thinking Skill Test was found to be appropriate for the main primary measurements or outcomes. Copyright permission was used for using the measurement outcomes, and publication was obtained for the standardized measurements. There were no secondary outcomes measured in the study.

Student Satisfaction and Self Confidence in Learning (SSSCL) was a 13-item questionnaire that used a five-point Likert scale to measure each item. The instrument measured satisfaction with simulation activity and self-confidence in learning ( 8 items). Five items were summed for a total score on the satisfaction with the current learning scale, with 25 points possible. An overall score was obtained for the self-confidence in learning scale, for a total possible score of 40 points from strongly disagree to agree strongly. Cronbach's alpha for satisfaction was 0.94 and self-confidence was 0.87 .

The Simulation Design Scale (SDS), was a 20 -item instrument using a 5-point scale from strongly disagree to strongly agree, designed to evaluate the five design features of the instructor-developed simulations used in the NLN/Laerdal study. The simulation design had two parts, importance and specific features which included the objectives/ information (5 items), problem-solving (5 items), student support/cues (4 items), guided reflection/debriefing/feedback ( 4 items), and fidelity to reality ( 2 items). Ten content experts established content validity in simulation development and testing. The SDS's reliability using Cronbach's alpha was 0.92 for features and 0.86 for importance in the study.

Educational Practice Questionnaire (EPQ), was a 16-item instrument using a 5-point scale from strongly disagree to strongly agree, and was designed to measure educational practices. Active learning (10 items), collaboration ( 2 items), diverse ways of learning ( 2 items), and high expectations ( 2 items) were present in the instructor-developed simulation and the importance of each practice to the learner. Reliability was tested using Cronbach's alpha, which was 0.84 for the presence of specific practices and 0.81 for the importance of particular practices.

Critical Thinking Skills Tool was measured by two valid and standardized critical thinking tools. The California Critical Thinking Disposition Inventory (CCTDI) was a 75-item Likert style attitudinal survey, ranging from 70 to 420 scores. $^{7}$ CCTDI covered truth-seeking, open-mindedness, analyticity, systematicity, CT self-confidence, 


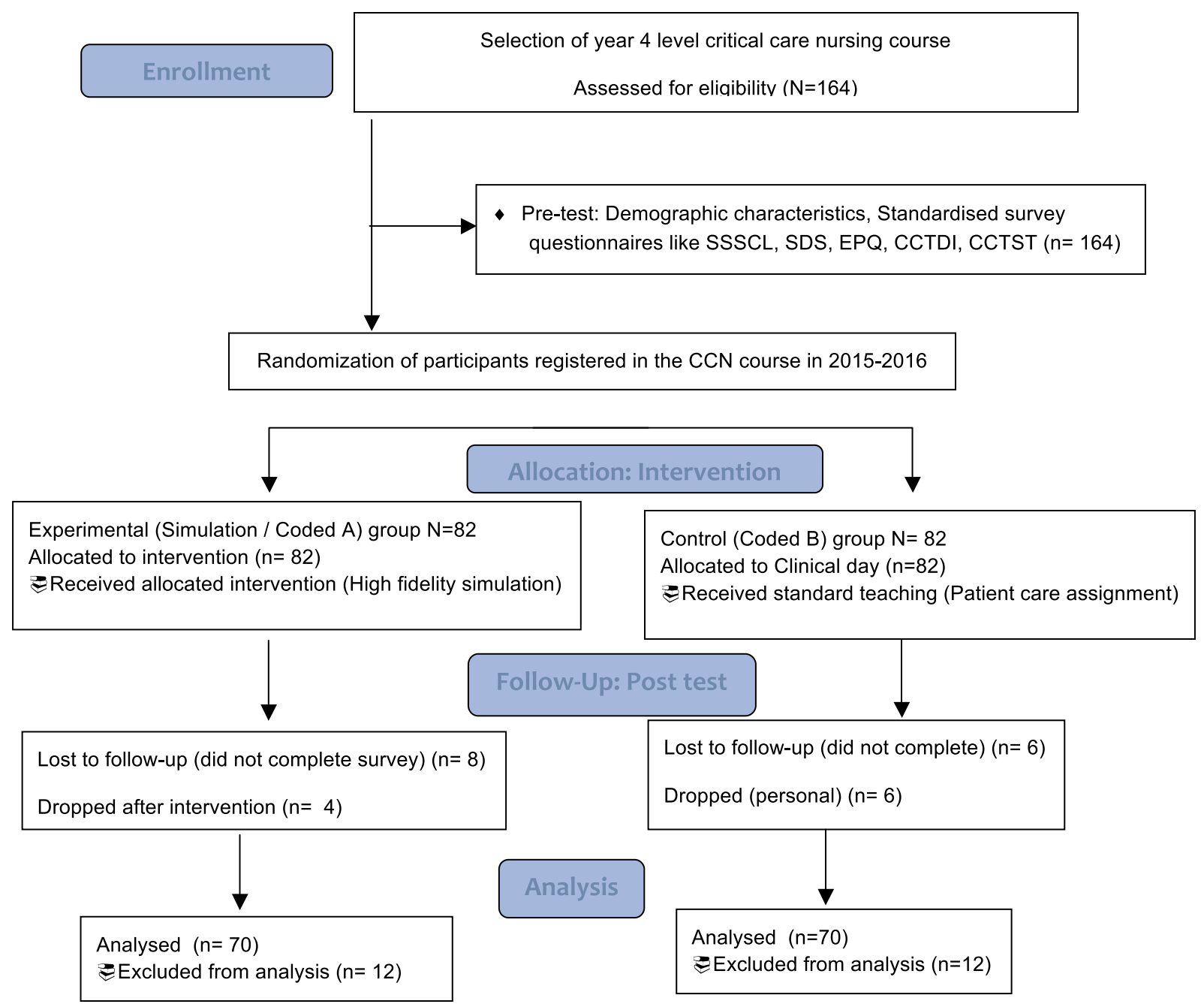

Fig. 1. CONSORT flow diagram.

inquisitiveness and maturity.

CCTDI had seven subscales, each designed to measure a critical thinking habit of mind, each subscale ranging from 10 to 60 . The reliability of the CCTDI using the alpha coefficient was 0.84 , and subscale coefficients ranged from 0.74 to 0.89 .

The California Critical Thinking Skill Test (CCTST) consisted of 34items that measured an individual's ability to draw a conclusion using inductive or deductive reasoning in the six areas of analysis, inference, evaluation, deductive, and inductive reasoning. ${ }^{8}$ CCTST captured gain scores in students' critical thinking. Each item was assigned to one of three subscales; analysis, inference, or evaluation. The reliability of the CCTST is 0.78 using the Kuder-Richardson-20.

Demographic characteristics included were age, gender, clinical experience and entry pathway.

\subsection{High-fidelity simulation intervention}

The clinical team of the critical care nursing (CCN) course developed, designed and piloted the high-fidelity simulation for the diabetes ketoacidosis (HFS-DKA) scenario with a random of 2 students from another course to test for feasibility and reliability. The validity of the HFS-DKA scenario was verified by a certified diabetes nurse educator, a registered nurse, and a clinical nurse educator. The HFS-DKA simulation teaching consisted of pre-briefing (an hour), running simulation (30 minutes) and debriefing (an hour) for the high-fidelity simulator using the Lardeal SIM man (Table 1). An hour was assigned for pre- briefing using unfolding case studies to promote knowledge exchange and share dialogues. The HFS crucial events and cues that would trigger problem identification, nursing assessment, starting actions/interventions, prioritizing, implementing and evaluating nursing care were run for 30 minutes. Debriefing was performed using a structured guideline for an hour by a clinical teacher.

In the simulation group, there were two independent groups of 6 students in each group who participated in the HFS-DKA for a 2.5 hours time duration on the simulation day each week. Each simulation group (first three students and next three students) entered the high-fidelity simulation room and was given a script of the case scenario, background and clinical patient information, and were exposed to the HFS mannequin on computerized cardiac monitoring. A total of 5 hours of HFS was used for the two randomly assigned simulation groups each week. Hence, a total of 40 hours of HFS was performed over 14 weeks for the 14 simulation groups starting in the third week of the CCN course from September 2015 to April 2016.

In the control group, there was one independent group of 6 students in one group who participated with clinical faculty supervision on a clinical day in an acute medical unit each week (Table 1). The control group had a pre-briefing for an hour by the clinical teacher who discussed diabetes ketoacidosis scenarios based on assessment/physical examination, nursing interventions, showed video-assisted teaching on diabetes ketoacidosis for 30 minutes and conducted a structured reflective practice for an hour. 
Table 1

Schedule for the simulation group and control group for the CCN course.

\begin{tabular}{|c|c|c|}
\hline Typical hours & Simulation Group (Coded A) & Control Group (Coded B) \\
\hline 0730-1030 & $\begin{array}{l}\text { Review of clinical lab skills: Providing cardiopulmonary resuscitation, Withdrawing } \\
\text { arterial blood gas, Titrating insulin infusion pumps }\end{array}$ & Patient assignment on acute medical unit \\
\hline $1130-1400$ & First three student's intervention: pre-briefing, simulation scenario and debriefing & Patient assignment on acute medical unit \\
\hline $1400-1630$ & Next three student's for intervention: pre-briefing, simulation scenario and a debriefing & $\begin{array}{l}\text { Six students for control group: pre-briefing, video assisted teaching } \\
\text { and a structured reflective practice }\end{array}$ \\
\hline
\end{tabular}

Table 2

Demographic characteristics among students in the simulation and control group $\mathrm{N}=140$.

\begin{tabular}{|c|c|c|c|c|c|c|c|}
\hline \multirow[t]{2}{*}{ Characteristics } & \multirow[t]{2}{*}{ Variables } & \multicolumn{2}{|c|}{ Simulation group $N=70$} & \multicolumn{2}{|c|}{ Control group $\mathrm{N}=70$} & \multirow[t]{2}{*}{ Chi square } & \multirow[t]{2}{*}{$P$ value } \\
\hline & & $\mathrm{N}=70$ & $\%$ & $\mathrm{~N}=70$ & $\%$ & & \\
\hline \multirow[t]{2}{*}{ Gender } & Male & 24.00 & 34.29 & 19.00 & 27.14 & 1.09 & $0.33^{\mathrm{ns}}$ \\
\hline & Female & 46.00 & 65.71 & 51.00 & 72.86 & & \\
\hline \multirow[t]{2}{*}{ Age (years) } & $19-25$ & 54.00 & 77.14 & 49.00 & 70.00 & 1.35 & $0.23^{\mathrm{ns}}$ \\
\hline & Above 25 years & 16.00 & 22.86 & 21.00 & 30.00 & & \\
\hline \multirow[t]{2}{*}{ Previous clinical experience } & No & 16.00 & 22.86 & 19.00 & 27.14 & 1.23 & $0.45^{\mathrm{ns}}$ \\
\hline & Yes & 54.00 & 77.14 & 51.00 & 72.86 & & \\
\hline \multirow[t]{2}{*}{ Entry pathway } & Graduate entry & 43.00 & 61.43 & 46.00 & 65.71 & 1.09 & $0.98^{\mathrm{ns}}$ \\
\hline & Post baccalaureate & 27.00 & 38.57 & 24.00 & 34.29 & & \\
\hline
\end{tabular}

$* \mathrm{P}<0.05$, not significant (ns).

\subsection{Ethical considerations}

Human ethics approval to conduct the randomized control trial was obtained from the institutional research and ethics review board (IG/ SQU/CN/AHCC/15/7/21). The study was registered in International Standard Randomized Controlled Trial Number ISRCTN12640591 https://doi.org/10.1186/ISRCTN12640591. Written informed consent for survey questionnaires, simulation intervention, audio and videotaping, and debriefing was obtained from voluntary participants. All the study data was confidential and was handled anonymously. The freedom to withdraw at any time during and after the study had not affected the learning and performance in the course. There were minimal potential risks in the study. Students were fully informed of the availability of a counsellor during the research study and could contact the ethics officer at any time during the study.

\subsection{Data collection}

One hundred sixty-four $(\mathrm{N}=164)$ students were registered in the CCN course from 2015 to 2016 . A baseline was conducted before the randomization and exposure to the HFS-DKA simulation teaching intervention for both the simulation and control groups. The pre-test consisted of students who met the eligibility criteria and completed a demographic profile, SSSCL, SDS, EPQ, CCTDI and CCTST survey questionnaires. The students in the $\mathrm{CCN}$ course were randomly assigned to the simulation group $(n=82)$ and the control group $(n=82)$ from 2015 to 2016. The post-test was conducted after four weeks of exposure to the HFS-DKA simulation teaching intervention for both the simulation and control groups. A post-baccalaureate student research assistant was trained for data collection, data management, and human ethics certified by the National Institutes of Health. The coded data was stored on an encrypted and password-protected computer, and the surveys were secured in a locked cabinet office. At the end of the study, manual surveys and digital data were destroyed.

\subsection{Data analysis}

Data analyses were performed with IBM SPSS Statistics 2017. A $t$ test and chi-square test were used for testing the homogeneity of the study participants, and for examining the mean scores in SSSCL, SDS, EPQ, CCTDI, and CCTST between the two groups. Pre-test baseline characteristics were analyzed using chi-square. The paired $t$-test was used to compare mean differences in satisfaction, self-confidence and critical thinking skills within groups. A two-way repeated-measures analysis of variance (ANOVA) was used to compare differences between the groups for changes in satisfaction, self-confidence and critical thinking skill scores. Two-way analysis of variance allowed the estimation of the effect of simulation teaching variable on the primary outcomes after controlling for the confounding effect of prior clinical experience. The effects of the HFS-DKA scenario were tested by examining the interaction effect, using partial eta-squared values $\left(\eta^{2}\right)$ values as a measure of group-by-time was interpreted as 0.06 as a moderate effect. All $p$ values were two-sided, and $p<0.05$ was considered statistically significant.

\section{Results}

One-hundred sixty-four $(\underline{N}=164)$ students were registered in the critical care nursing (CCN) courses from 2015 to 2016. A total of 140 (85.5\%) students completed the research study.

\subsection{Sample characteristics}

The majority of the students were female in the simulation group (65.71\%) and the control group (72.86\%) (Table 2). Most of the students were enrolled in undergraduate nursing in the simulation group $(61.43 \%)$ and the control group $(65.71 \%)$. There were no significant differences between the demographic characteristics in the simulation and control group.

\subsection{Student Satisfaction and Self Confidence in Learning, Simulation Design Scale, educational practice questionnaire (SSSCL, SDS, and EPQ)}

The post-test mean scores of Student satisfaction with learning $(\overline{\mathrm{x}}=25.0 \pm 2.13$ vs $21.8 \pm 2.84)$, Self-confidence in learning $(\overline{\mathrm{x}}=$ $35.8 \pm 2.45$ vs $26.7 \pm 5.61)$, Objectives and information $(\overline{\mathrm{x}}=$ $25.0 \pm 2.03$ vs $20.3 \pm 3.41$ ) of Simulation Design, and Active learning $(\bar{x}=45.3 \pm 3.38$ vs $24.7 \pm 5.5)$ of Education Practice Questionnaire were significantly higher in the simulation compared to the control group (Table 3). 
Table 3

Student satisfaction and self confidence in learning, simulation design scale, and educational practice questionnaire $\mathrm{N}=140$.

\begin{tabular}{|c|c|c|c|c|c|c|c|c|}
\hline & Pre-test & & & & Post-test & & & \\
\hline Measures & Simulation & Control & $t$-test & $\mathrm{p}$ & Simulation & Control & $t$-test & $\mathrm{p}$ \\
\hline Student Satisfaction and Self Confidence in Learning & Mean \pm SD & Mean + SD & $t$-test & $\mathrm{p}$ & Mean \pm SD & Mean \pm SD & $t$-test & $\mathrm{p}$ \\
\hline Satisfaction with current learning (5-25) & $23.3 \pm 1.23$ & $19.8 \pm 2.1$ & 2.23 & 0.55 & $25.0 \pm 2.13$ & $21.8 \pm 2.84$ & -1.23 & $0.05^{*}$ \\
\hline Self-confidence in learning (8-40) & $32.8 \pm 2.3$ & $28.7 \pm 3.6$ & 2.03 & 0.34 & $35.8 \pm 2.45$ & $26.7 \pm 5.61$ & -1.03 & $0.04 *$ \\
\hline \multicolumn{9}{|l|}{ Simulation Design Scale } \\
\hline Objectives and information (5-25) & $23.6 \pm 1.23$ & $17.3 \pm 3.4$ & 2.8 & 0.58 & $25.0 \pm 2.03$ & $20.3 \pm 3.41$ & 1.17 & $0.05^{*}$ \\
\hline Support (4-20) & $16.4 \pm 12.3$ & $10.2 \pm 3.4$ & 1.12 & 0.73 & $20 \pm 6.30$ & $11.2 \pm 4.4$ & 2.32 & 0.73 \\
\hline Problem solving (5-25) & $22.4 \pm 19.3$ & $13.4 \pm 6.4$ & 1.23 & 0.46 & $25 \pm 8.3$ & $15.4 \pm 9.30$ & 3.43 & $0.04^{*}$ \\
\hline Feedback/Guided reflection (4-20) & $16.5 \pm 13.2$ & $12.4 \pm 3.4$ & 3.56 & 0.21 & $20 \pm 8.2$ & $15.4 \pm 6.40$ & -3.87 & $0.03 *$ \\
\hline Fidelity/Realism (2-10) & $9.3 \pm 1.45$ & $7.6 \pm 2.3$ & 3.23 & 0.44 & $12.3 \pm 2.45$ & $9.6 \pm 3.3$ & -2.13 & 0.44 \\
\hline \multicolumn{9}{|l|}{ Educational Practice Questionnaire } \\
\hline Active learning (10-50) & $42.3 \pm 2.3$ & $26.7 \pm 4.5$ & 2.45 & 0.25 & $45.3 \pm 3.38$ & $24.7 \pm 5.5$ & 1.45 & $0.05^{*}$ \\
\hline Collaboration $(2-10)$ & $8.5 \pm 0.34$ & $3.6 \pm 3.4$ & 2.09 & 0.14 & $10 \pm 1.64$ & $4.6 \pm 3.40$ & 0.09 & 0.14 \\
\hline Diverse ways of learning (2-10) & $8.3 \pm 2.3$ & $4.5 \pm 4.3$ & 2.09 & 0.90 & $10 \pm 2.13$ & $4.5 \pm 4.3$ & 0.09 & 0.90 \\
\hline High expectations (2-10) & $8.5 \pm 1.3$ & $4.5 \pm 2.3$ & 1.23 & 0.76 & $10 \pm 2.35$ & $4.5 \pm 2.3$ & 2.23 & 0.76 \\
\hline
\end{tabular}

$* \mathrm{P}<0.05$, Standard Deviation (SD).

\subsection{Critical thinking skills tool and the California Critical thinking skill (CCTDI and CCTST)}

California Critical thinking disposition (CCTDI) and Critical thinking skill (CCTST) post-test subscale mean scores for Analyticity $(\overline{\mathrm{x}}=45.78 \pm 5.64$ vs $35.72 \pm 5.64)$, Self-confidence $(\bar{x}=45.45 \pm 4.56$ vs $43.30 \pm 4.56)$ and Maturity $(\bar{x}=48.40 \pm 4.56$ vs $37.91 \pm 4.56$ ) were higher in the students exposed to HFS scenario for diabetes ketoacidosis in the simulation group compared to the control group respectively (Table 4). Post-test mean CCTST subscale scores for Analysis $(\bar{x}=8.24+2.34$ vs $6.30 \pm 4.34)$, Induction $(\bar{x}=9.64 \pm 3.45$ vs $8.54 \pm 3.45)$, and Deduction $(\bar{x}=8.67 \pm 3.45$ vs $7.67 \pm 3.45$ ) were higher in the students exposed to HFS scenario for diabetes ketoacidosis in the simulation group compared to the control group respectively. The total CCTDI and the CCTST post-test mean scores were significantly higher in the simulation compared to the control group.

\subsection{SSSCL, SDS, EPQ CCTDI, and CCTST}

The post-test mean scores of Student Satisfaction in Learning $(\overline{\mathrm{x}}=4.23 \pm 0.39$ vs $3.30 \pm 0.85)$, Self-confidence in learning $(\bar{x}=3.79 \pm 0.74$ vs $3.28 \pm 0.28)$, Simulation Design $(\bar{x}=4.35 \pm 0.75$ vs $2.98 \pm 0.23$ ), Education Practice Questionnaire ( $\bar{x}=3.95 \pm 0.75$ vs $2.98 \pm 0.24)$, California critical thinking disposition inventory $(\bar{x}=3.45 \pm 0.75$ vs $2.98 \pm 0.34)$ and the California critical thinking skill test $(\bar{x}=3.12 \pm 0.83$ vs $2.77 \pm 0.30)$ were significantly higher in the simulation compared to the control group (Table 5). The post-test mean scores of Critical thinking disposition inventory and Critical thinking skill test were significantly higher in simulation compared to the control group.

The results of the two-way ANOVA on Student Satisfaction in Learning score showed a significant interaction between groups and time. Analysis of simple main effect test results showed a statistical difference between the groups in the post-test $(p=0.05)$ and a

Table 4

California Critical Thinking Disposition Inventory and California Critical Thinking Skill Test scores N = 140 .

\begin{tabular}{|c|c|c|c|c|c|c|}
\hline \multirow[b]{2}{*}{ Measures } & \multicolumn{2}{|c|}{ Simulation group $N=70$} & \multirow{2}{*}{$\begin{array}{l}\text { Control group } \\
\text { Pretest }\end{array}$} & \multirow{2}{*}{$\begin{array}{l}\mathrm{N}=70 \\
\text { Post-test }\end{array}$} & \multicolumn{2}{|c|}{ Post-test comparison ${ }^{\#}$} \\
\hline & Pretest & Post-test & & & $t$-test & $\mathrm{p}$ value \\
\hline CCTDI subscales & Mean (SD) & Mean (SD) & Mean (SD) & Mean (SD) & & \\
\hline Truth seeking & 39.45 (4.67) & $41.38(5.34)$ & $35.95(5.67)$ & $31.39(5.34)$ & 1.75 & 0.41 \\
\hline Open-mindedness & $38.43(4.67)$ & $44.40(4.83)$ & $34.05(5.67)$ & $34.48(4.83)$ & 0.45 & 0.24 \\
\hline Analyticity & $34.95(4.35)$ & $45.78(5.64)$ & $30.95(6.35)$ & $35.72(5.64)$ & 1.34 & $0.02 *$ \\
\hline Systematicity & $32.67(5.94)$ & $43.51(5.06)$ & $29.67(4.94)$ & $41.28(5.06)$ & 1.23 & 0.23 \\
\hline Self-confidence & $32.46(4.56)$ & $45.45(4.56)$ & $28.65(9.56)$ & $43.30(4.56)$ & 0.45 & $0.05^{*}$ \\
\hline Inquisitiveness & $33.41(4.56)$ & $46.57(5.46)$ & $34.25(8.56)$ & $43.48(5.46)$ & 2.34 & 0.34 \\
\hline Maturity & $40.34(4.56)$ & $48.40(4.56)$ & $36.44(6.56)$ & $37.91(4.56)$ & 0.45 & 0.07 \\
\hline Total CCTDI score & $295.56(29.34)$ & 314.64 (17.56) & $267.06(25.34)$ & $285.07(24.56)$ & 2.34 & $0.05^{*}$ \\
\hline \multicolumn{7}{|l|}{ CCTST subscales } \\
\hline Analysis & $7.32(2.34)$ & $8.24(2.34)$ & $5.34(3.34)$ & $6.30(4.34)$ & 2.34 & $0.05^{*}$ \\
\hline Inference & $3.49(2.34)$ & $5.86(2.03)$ & $5.25(4.34)$ & $9.40(5.03)$ & 1.02 & 0.34 \\
\hline Evaluation & $9.67(2.34)$ & $10.34(2.34)$ & $5.67(5.34)$ & $6.94(5.34)$ & 2.76 & 0.45 \\
\hline Induction & $3.41(3.45)$ & $9.64(3.45)$ & $8.45(4.45)$ & $8.54(3.45)$ & 0.45 & $0.02 *$ \\
\hline Deduction & $4.45(3.45)$ & $8.67(3.45)$ & $9.75(5.45)$ & $7.67(3.45)$ & 2.34 & $0.05^{*}$ \\
\hline Total CCTDT score & $9.55(4.35)$ & $10.23(4.56)$ & $8.35(6.35)$ & $9.03(8.56)$ & 2.45 & $0.05^{*}$ \\
\hline
\end{tabular}

${ }^{*} \mathrm{P}<0.05$, Standard Deviation (SD), ${ }^{*}$ Post-test comparison between simulation and control groups.

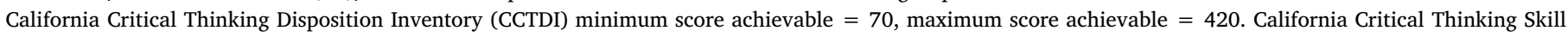
Test (CCTST) minimum score achievable $=0$, maximum score achievable $=34$.

$<25$ th percentile of scores $=$ weak critical thinking disposition/skills.

$<25$ th to 74 th percentile of scores $=$ average critical thinking disposition/skills.

$>75$ th percentile of score $=$ strong critical thinking disposition/skills. 
Table 5

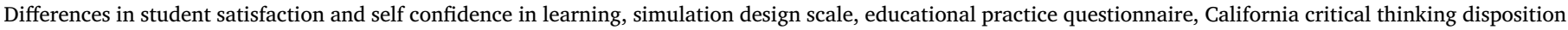
inventory and California critical thinking skill test comparison $\mathrm{N}=140$.

\begin{tabular}{|c|c|c|c|c|c|c|c|c|}
\hline \multirow{2}{*}{$\begin{array}{l}\text { Measures } \\
\text { Time }\end{array}$} & \multicolumn{2}{|c|}{ Simulation group $\mathrm{N}=70$} & \multicolumn{2}{|c|}{ Control group $\mathrm{N}=70$} & \multicolumn{4}{|c|}{ Two-way analysis of variance } \\
\hline & Pre-test & Post-test & Pre-test & Post-test & & Groups & Time & Groups $\mathrm{x}$ Time \\
\hline Mean + SD & $\mathrm{M} \pm \mathrm{SD}$ & $\mathrm{M} \pm \mathrm{SD}$ & $\mathrm{M} \pm \mathrm{SD}$ & $\mathrm{M} \pm \mathrm{SD}$ & F-value & & & \\
\hline \multirow[t]{3}{*}{ Student Satisfaction in Learning } & $2.98 \pm 0.34$ & $4.23 \pm 0.39$ & $3.12 \pm 0.24$ & $3.30 \pm 0.85$ & F-value & 29.22 & 43.24 & 21.34 \\
\hline & & & & & $P$ value & $0.05^{*}$ & $0.05^{*}$ & $0.04^{*}$ \\
\hline & & & & & $\eta^{2}$ & 0.32 & 0.31 & 0.36 \\
\hline \multirow[t]{3}{*}{ Student Self Confidence in Learning } & $3.24 \pm 0.34$ & $3.79 \pm 0.74$ & $3.45 \pm 0.34$ & $3.28+0.28$ & F-value & 47.19 & 53.34 & 58.58 \\
\hline & & & & & $P$ value & $0.04 *$ & $0.04 *$ & $0.05^{*}$ \\
\hline & & & & & $\eta^{2}$ & 0.42 & 0.67 & 0.61 \\
\hline \multirow[t]{3}{*}{ Simulation Design Scale } & $2.45 \pm 0.25$ & $4.35 \pm 0.75$ & $2.87 \pm 0.67$ & $2.98 \pm 0.23$ & F-value & 47.32 & 87.27 & 51.30 \\
\hline & & & & & $P$ value & $0.06^{*}$ & $0.06^{*}$ & $0.04 *$ \\
\hline & & & & & $\eta^{2}$ & 0.63 & 0.65 & 0.58 \\
\hline \multirow[t]{3}{*}{ Educational Practice Questionnaire } & $3.45 \pm 0.25$ & $3.95 \pm 0.75$ & $3.07 \pm 0.37$ & $2.98 \pm 0.24$ & F-value & 54.61 & 65.29 & 24.56 \\
\hline & & & & & $P$ value & $0.06^{*}$ & $0.06^{*}$ & $0.05^{*}$ \\
\hline & & & & & $\eta^{2}$ & 0.58 & 0.73 & 0.41 \\
\hline \multirow[t]{3}{*}{ California Critical Thinking Disposition Inventory } & $3.15 \pm 0.43$ & $3.45 \pm 0.75$ & $2.97 \pm 0.26$ & $2.98 \pm 0.34$ & F-value & 90.42 & 61.48 & 95.45 \\
\hline & & & & & $P$ value & $0.02 *$ & $0.02 *$ & $0.00 *$ \\
\hline & & & & & $\eta^{2}$ & 0.85 & 0.73 & 0.72 \\
\hline \multirow[t]{3}{*}{ California Critical Thinking Skill Test } & $2.87 \pm 0.35$ & $3.12 \pm 0.83$ & $2.77 \pm 0.34$ & $2.77 \pm 0.30$ & F-value & 32.35 & 45.34 & 45.67 \\
\hline & & & & & $P$ value & $0.03 *$ & $0.04 *$ & $0.00^{*}$ \\
\hline & & & & & $\eta^{2}$ & 0.75 & 0.45 & 0.34 \\
\hline
\end{tabular}

Note. Two-way analysis of variance for $\times p$ value $<0.05$ for level of significance, partial eta squared $\left(\eta^{2}\right)$, Standard Deviation $(S D)$.

significant difference in the simulation group $(p=0.05)$. The estimated effect size was moderate $\left(\eta^{2}=0.36\right)$. The results of the two-way ANOVA for Student Self Confidence in Learning showed a significant interaction between groups and time. Analysis of simple main effect test results showed a significant difference between groups post-test $(p=0.04)$ and a significant difference $(p=0.04)$ over time in the simulation group. The estimated effect size was large for improvements in student self-confidence $\left(\eta^{2}=0.61\right)$.

The results of the two-way ANOVA on the California Critical Thinking Disposition Inventory showed a significant interaction between groups and time. Analysis of simple main effect test results showed a significant difference $(p=0.02)$ between the groups post-test and overtime in the simulation group $(\mathrm{p}=0.02)$. The estimated effect size was moderate $\left(\eta^{2}=0.72\right)$. The results of the two-way ANOVA on the California Critical Thinking Skill Test showed a significant interaction between groups and time. Analysis of simple main effect test results showed a significant difference $(p=0.03)$ between the groups post-test and overtime in the simulation group $(\mathrm{p}=0.04)$. The estimated effect size was moderate $\left(\eta^{2}=0.34\right)$.

\section{Discussion}

In this study, the majority of the students were below 25 years in the undergraduate nursing program. This refers to consistency with previous studies on younger students who have shown high critical thinking in analysis and reasoning. ${ }^{9}$ In this study, students less than 25 years had significantly higher scores in self-confidence and satisfaction, which supports the use of simulation in preparing undergraduate students to face real-world situations in emergencies and practice in an anxiety-free, and safe environment. In this study, students with past high-fidelity simulation experience achieved higher post-test mean scores of student satisfaction and self-confidence in learning in the simulation group. Students reported better knowledge through the highfidelity simulation teaching intervention compared to traditional clinical settings over time. Students in the HFS intervention group had better performance and had increased knowledge and performance ${ }^{10,11}$ compared to the control group. These differences showed that the HFSDKA had contributed to improving knowledge and critical thinking in the simulation group.

The post-test mean scores for the Satisfaction with current learning and Self-confidence in learning was significantly higher and indicated that the learning environment was satisfactory. The students in this study had a hands-on experience (learning by doing and collaborative learning) and video recording, which displayed higher post-test mean scores on objectives, problem-solving and feedback/guided reflection, an essential part of the simulation design. HFS improved technical, clinical skills, teamwork and intervening effectively in emergency situations. ${ }^{12}$ Hence, students in the simulation group valued interactive guided reflection and fidelity. These results indicate that the HFS-DKA scenario enabled students to acquire self-confidence in the simulation and education practices in realistic situations and to interact with HFS. In this study, fidelity/realism of the HFS-DKA scenario was a critical design feature for an independent role and has had a positive effect on the ability of the student to use their critical thinking, clinical reasoning and problem solving with faculty support and collaboration.

The study findings confirm the value of HFS-DKA scenarios for teaching and learning in a safe and controlled learning environment for the simulation group. Novice student's entry into clinical require baseline knowledge for safe clinical practice, and HFS enhanced critical thinking. ${ }^{13,14}$ Students achieved good knowledge, skill performance and physical assessment. ${ }^{15}$ The HFS-DKA scenario experience provided students with an opportunity to develop critical thinking skills and resulted in an increased self-confidence in the simulation group. The critical thinking scores significantly improved using the HFS-DKA scenario, indicating a stronger critical thinking disposition and cognitive skills with a more exceptional ability for analyticity, self-confidence, maturity, analysis, induction and deduction reasoning.

In this study, supportive and diverse ways of learning provided a chance for achieving objectives/information and problem-solving while teaching concepts using problem identification, logic of argument, synthesis and problem-solving in assessing, planning and intervening in the DKA patient care scenario that are difficult to integrate and learn effectively on an acute and critical care setting. There was a significant improvement in knowledge and self-confidence in the post-test as compared to the pre-test ${ }^{16,17}$ and a more extended period of knowledge retention and self-confidence credited to repeated simulation teaching ${ }^{18}$ (Orique and Phillips, 2018). In this study, HFS reproduced an actual clinical scenario and promoted critical thinking through interpretation, analysis and inference and to clinical practice. Objectives/ information was a strong predictor of satisfaction with HFS. ${ }^{19,20}$ Selfconfidence skills among the students improved using critical cues and problem identification. ${ }^{21,22}$ 
In the study, students were satisfied with the simulation design and education practice, conveying a decisive engagement in the orientation/pre-briefing, integration of the implementation/simulation activity, and demonstration of reflection/debriefing through an efficient sequence of supportive assessment, critical analysis and active learning experiences. A dynamic and interactive learning environment encourages students to make connections using essential thinking disposition, critical thinking skills, and analyzing abilities for the flow of acute events in the HFS-DKA scenario. Debriefing included was a proactive approach through reinforcements and sustaining the learning experiences by improving critical thinking, higher satisfaction, and guided reflection for nursing care. ${ }^{23}$ The observation role is vital as the active roles, which makes simulation a practical teaching strategy. ${ }^{15}$ In our study, debriefing after the HFS-DKA scenario was led by immediate, focused and structured feedback and learning by doing by a qualified clinical teacher who was found to be effective in the simulation group.

Students demonstrated communication and technical skills, ${ }^{24}$ cognitive and affective learning ${ }^{25}$ and active in different roles. ${ }^{26}$ In our study, students in the simulation group were active and benefited from small groups through observation, interaction and constructive feedback from faculty. This study shows that a smaller group of students achieved higher critical thinking disposition and critical thinking skills that correlated with the self-confidence, simulation design, and education practice questionnaires with a hands-on learning experience. The higher post-test means score of commitment objectives/information and support, problem-solving could be attributed to the student's ability to achieve critical thinking. A focused, consistent and structured learning environment was manifested by a direct association and a positive correlation between satisfaction and self-confidence in learning, simulation design, and an educational practice questionnaire.

Limitations from the study include that it is difficult to judge the learner's improvement in critical thinking by the simulation teaching; critical thinking disposition and skills need a specific time to be acquired, and it does not seem to improve in a limited time.

\section{Conclusions}

High fidelity simulation-diabetes ketoacidosis (HFS-DKA) scenario provided an enriched learning experience that led to improved student learning outcomes in the simulation group. In smaller HFS groups, students play collaborative roles acting as team nurses, problem-solving, active learning and diverse ways of knowledge that can increase the learning significance. Fidelity and realism appeared to positively affect the students' abilities to use their creativity, learn from each other in a safe and controlled learning environment. The findings implied the attainment of the simulation experience dependent on the quality of the simulation design and the educational practices with opportunities to care for clients with diabetes ketoacidosis in HFS mirroring critical care nursing.

High-fidelity simulation augmented the amalgamation of educational outcomes in critical care nursing. It ameliorated the students to learn about diabetes ketoacidosis and to support them in applying critical thinking to future practice. The HFS based on the learning objectives of the course and is a characteristic of simulation design, and clear goals are integrated within the curriculum. Novice nursing students, who are trying to master assessment and management in critical care nursing will be aware and sensitized to challenges in acute and emergency scenarios to make an appropriate judgement, and efficiently think, do and act. Hence, simulation teaching intervention can be incorporated to improve analytical skills within a well-designed structured pre-briefing, simulation and debriefing simulation.

\section{Summary Statement}

What is already known about the topic.
- Students have fewer experiences while caring for clients in acute emergencies like diabetes ketoacidosis in a clinical unit.

- Simulation is an innovative teaching strategy to provide realistic experiences to mimic acute medical and surgical nursing conditions.

- Successful educational outcomes include an increase in knowledge, performance, and communication skills.

What this paper adds.

- High fidelity simulation scenarios can provide an enriched learning experience and a valuable interactive pedagogy for diabetes ketoacidosis.

- Higher critical thinking scores indicate analytical and conceptual thinking using essential thinking disposition among students.

- Self-confidence and self-satisfaction are essential in developing critical thinking, responding to changing assessments and a readiness to intervene.

\section{Implications.}

- High-fidelity simulation is a crucial teaching-learning strategy that is useful to visualize emergencies like diabetes ketoacidosis.

- High-fidelity simulation can be integrated into critical care nursing to promote knowledge and performance for safe nursing care.

- A well-designed simulation teaching can be incorporated in nursing for improving critical thinking for decision-making.

\section{Authorship and contributions}

MSD, LJL, KP, RV, and SNK have made substantial contributions on the conception, design, acquisition of data, and analysis and interpretation of data. MSD have drafted the article and revised it critically for important intellectual content. All the five authors have agreed on the final version of the submitted paper. Melba Sheila D'Souza (MSD), Leodoro Jabien Labrague (LJL), Kader Parahoo (KP), Ramesh Venkatesaperumal (RV), and Subrahmanya Nairy Karkada (SNK).

\section{Ethical approval of studies and informed consent}

This study was supported by Internal Grant, Sultan Qaboos University [IG/SQU/CN/AHCC/15/7/21]. The study was registered in the International Standard Randomized Controlled Trial Number: ISRCTN12640591 https://doi.org/10.1186/ISRCTN12640591.

The views expressed in this study do not necessarily represent the views of the CON, SQU. We are grateful to the consultants, content validators, research assistants, and professional language editors. All participants gave informed consent for the research, and that their anonymity and confidentiality was preserved.

\section{Funding support statement}

This work was supported by the internal grant from the Sultan Qaboos University [Grant number IG/SQU/CN/AHCC/15/7/21]. The sponsors played no role in the design, execution, analysis, data interpretation, writing reports or decision to submit the paper for publication.

\section{Code of ethics in publishing}

The study has been approved by the College of Nursing Research and Ethics Committee, and the Sultan Qaboos University Review Board. The code of ethics is in accordance with the World Medical Association (Declaration of Helsinki) for experiments and the uniform requirements of the Biomedical journal. 


\section{Copyright transfer agreement}

We agree to the copyright of the Author Licensing Service, Journal publishing agreement and will sign the Copyright Transfer Agreement.

\section{Submission declaration}

This article has not been submitted to any journal and the work described has not been published previously in any form and is not under consideration of publication elsewhere.

\section{Language}

This paper has been edited with the language editor to conform to correct scientific English.

\section{Submission checklist}

We have adhered to the journal author guidelines.

High fidelity simulation - Diabetes ketoacidosis.

\section{Declaration of competing interest}

None, there are no financial, personal or other conflicts of interest has been declared by all the authors. ICMJE form for disclosure of potential conflicts of interest will be submitted by the authors.

\section{Acknowledgements}

We acknowledge the valuable teaching, intervention, and suggestions of the critical care nursing course teachers, clinical simulation laboratory technicians, and registered nurses.

\section{References}

1. Perez Amelia. High-fidelity mannequin simulation versus virtual simulation for recognition of critical events by student registered nurse anesthetists. AANA J (Am Assoc Nurse Anesth). 2019 Apr 1;87(2):105-109.

2. Williams T. Using high fidelity simulation to prepare baccalaureate nursing students enrolled in a historically black College and university. ABNF J. (Assoc. Black Nurs. Fac.). 2019 Apr 1;30(2)

3. Allen ML. Examining nursing students' stress in an end-of-life care simulation. Clinical Simulation in Nursing. 2018 Jan 1;14:21-28.

4. Fabro K, Schaffer M, Scharton J. The development, implementation, and evaluation of an end-of-life simulation experience for baccalaureate nursing students. Nurs Educ Perspect. 2014 Jan 1;35(1):19-25.

5. Andrea J, Kotowski P. Using standardized patients in an undergraduate nursing health assessment class. Clinical Simulation in Nursing. 2017 Jul 1;13(7):309-313.

6. Adamson KA, Kardong-Edgren S, Willhaus J. An updated review of published simulation evaluation instruments. Clinical Simulation in Nursing. $2013 \mathrm{Sep}$ 1;9(9):e393-400.
7. Facione NC, Facione PA, Sanchez CA. Critical thinking disposition as a measure of competent clinical judgment: the development of the California Critical Thinking Disposition Inventory. J Nurs Educ. 1994;33(8):345-350.

8. Facione NC, Facione PA. Critical Thinking and Clinical Judgment. Critical Thinking and Clinical Reasoning in the Health Sciences: A Teaching Anthology. 2008; 2008:1-13.

9. Hunter S, Pitt V, Croce N, Roche J. Critical thinking skills of undergraduate nursing students: description and demographic predictors. Nurse Educ Today. 2014 May 1;34(5):809-814.

10. Berger C, Brinkrolf P, Ertmer C, et al. Combination of problem-based learning with high-fidelity simulation in CPR training improves short and long-term CPR skills: a randomised single blinded trial. Bio Med Central Medical Education. 2019 Dec;19(1):180.

11. Parsons SM, Kuszajewski ML, Merritt DR, Muckler VC. High-fidelity simulation training for nurse anesthetists managing malignant hyperthermia: a quality improvement project. Clinical Simulation in Nursing. 2019 Jan 1;26:72-80.

12. Gosselin É, Marceau M, Vincelette C, Daneau CO, Lavoie S, Ledoux I. French translation and validation of the mayo high performance teamwork scale for nursing students in a high-fidelity simulation context. Clinical Simulation in Nursing. 2019 May 1;30:25-33.

13. Shin H, Ma H, Park J, Ji ES, Kim DH. The effect of simulation courseware on critical thinking in undergraduate nursing students: multi-site pre-post study. Nurse Educ Today. 2015 Apr 1;35(4):537-542.

14. Kim E. Effect of simulation-based emergency cardiac arrest education on nursing students' self-efficacy and critical thinking skills: roleplay versus lecture. Nurse Educ Today. 2018 Feb 1;61:258-263.

15. Tamaki T, Inumaru A, Yokoi Y, et al. The effectiveness of end-of-life care simulation in undergraduate nursing education: a randomized controlled trial. Nurse Educ Today. 2019 May 1;76:1-7.

16. Massoth C, Röder H, Ohlenburg H, et al. High-fidelity is not superior to low-fidelity simulation but leads to overconfidence in medical students. BMC Med Educ. 2019 Dec;19(1):29.

17. D'Souza RM, Venkatesaperumal R, Chavez F, Parahoo K, Jacob D. Effectiveness of simulation among undergraduate students in the critical care nursing. International Archives of Nursing and Health Care. 2017;3(4):1-8.

18. Orique SB, Phillips LJ. The effectiveness of simulation on recognizing and managing clinical deterioration: meta-analyses. West J Nurs Res. 2018 Apr;40(4):582-609.

19. Zhu FF, Wu LR. The effectiveness of a high-fidelity teaching simulation based on an NLN/Jeffries simulation in the nursing education theoretical framework and its influencing factors. Chin Nurs Res. 2016 Sep 1;3(3):129-132.

20. D'Souza MS, Arjunan P, Venkatesaperumal R. High fidelity simulation in nursing education. Int J Health Sci Res, 2017;7(7):340-353.

21. Rodriguez L. A Mixed Method Study of the Impact and Outcomes of Graduates of the CSU Northern California Consortium Doctor of Nursing Practice Program Class of. 2014; 2014.

22. Ahn H, Kim HY. Implementation and outcome evaluation of high-fidelity simulation scenarios to integrate cognitive and psychomotor skills for Korean nursing students. Nurse Educ Today. 2015 May 1;35(5):706-711.

23. Mariani B, Cantrell MA, Meakim C, Prieto P, Dreifuerst KT. Structured debriefing and students' clinical judgment abilities in simulation. Clinical Simulation in nursing. 2013 May 1;9(5):e147-e155.

24. Fioravanti MA, Hagle H, Puskar K, et al. Creative learning through the use of simulation to teach nursing students screening, brief intervention, and referral to treatment for alcohol and other drug use in a culturally competent manner. $J$ Transcult Nurs. 2018 Jul;29(4):387-394.

25. Ozkara San E. Effect of the Diverse Standardized Patient Simulation (DSPS) cultural competence education strategy on nursing students' transcultural self-efficacy perceptions. J Transcult Nurs. 2019 May;30(3):291-302.

26. Wang AL, Fitzpatrick JJ, Petrini MA. Comparison of two simulation methods on Chinese BSN students' learning. Clinical Simulation in Nursing. 2013 Jun 1;9(6):e207-e212. 